\title{
To succeed as youth athlete: Is it the dead end in track and field?
}

\author{
M. Moreno a, J. Jiménez-Díaz a, ${ }^{*}$, W. Salazar a \\ a School of Physical Education and Sports, University of Costa Rica, San José, Costa Rica \\ *Corresponding author Email: judith.jimenez d@ucr.ac.cr \\ DOI: https://doi.org/10.34256/ijpefs2132 \\ Received: 17-04-2021, Revised: 03-07-2021; Accepted: 05-07-2021; Published: 08-07-2021
}

Abstract: It is reasonable to believe that a young athlete who succeeds in a World Youth Championship, will also be successful as a senior athlete. To determine the percentage of success of all World Youth Championship finalists who also became finalists in a subsequent senior World Championship, considering all athletes and events at World Athletics Championships. This study analyzed the eight male and eight female finalists of all the events conducted at the World Athletics World Youth Championship from 1999 to 2009, who also became finalists at the World Athletics World Championship from 2001 to 2011. Percentage of success was calculated for track and field events, for male, female, and both. For all the events, from 1759 finalists in a World Youth Championship only 83, representing 4.72\%, were also finalists in a World Championship in 2001, 2003, 2005, 2007, 2009, or 2011. Of those 83 athletes, 45 were males and 38 were female. A low rate of success was found. These results were discussed including injuries, early specialization, biological maturation, and/or overtraining, as possible factors related to this low rate of success.

Keywords: Sports, Performance, Elite Athlete, World Championship

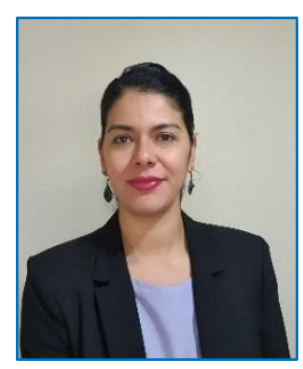

Ms. María Moreno, Has a degree in Nutrition from de Universidad Veracruzana, with a master's degree in Human Movement Science, from the University of Costa Rica, and a master's degree in Integral Health, from the National University in Costa Rica. Triathlon Coach from the Mexican Triathlon Federation (FMTRI). Recently, teaches classes of Sports Nutrition and Nutritional Assessments.

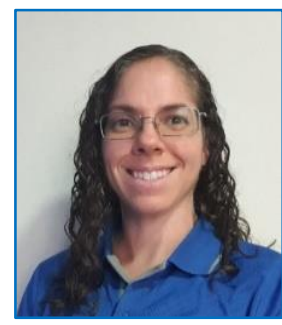

Dr. Judith Jiménez-Díaz, is a Physical Education Teacher; with a Ph.D. in Human Movement Science, with an emphasis in motor development and learning. She worked in preschool and elementary school for over 10 years. And has been a professor at the University of Costa

Rica for 12 years.

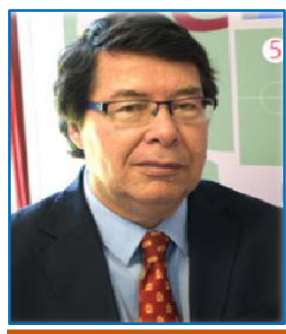

Dr. Walter Salazar, He has a master's degree in Human Performance from the University of Indiana and a Ph.D. in Exercise Science from the Arizona State University. He has been a professor and researcher at the University of Costa Rica for over 25 years. He performed as
Olympic Coach for the Costa Rican National Track and Field Team in the Olympics Games of 1996, 2008, 2012, and 2016.

\section{Introduction}

World championships (WC) in Athletics have been organized by Word Athletics (WA; formerly International Association of Athletics Federations IAAF-) since 1983. In 1986, the WA introduced the WA World Junior/U20 Championships (WJC), which are held for 18 and 19-year-old athletes. Moreover, the WA World Youth/U18 Championship (WYC) for 16 and 17year-old athletes was firstly held in 1999.

The WA World Youth Championships have people that support the event, but also there are people opposed to it. The supporters for the WA WYC believed that the new event would promote goaloriented training. On the contrary, the opponents believed that the event might produce early specialization, which would lead to injuries before athletes reached their performance peak [1]. Therefore, for the past years, research has analyzed the percentage of young and junior athletes who competed and were successful at WA WYC or WJC, and became successful at a WC. 
Several studies have revealed that only a small percentage of successful youth athletes, became also successful at a senior level [1-4]. A recent study found that, approximately $10-25 \%$ of the top-level Italian adult athletes in jumping events, were also top-level young athletes, at the age of 16 [2]. Similarly, when analyzing women's career in the Portuguese top five (Portuguese rankings), only a $13 \%$ of the youth athletes had success as senior athletes. In addition, they conclude that the lowest results were found in the throwing events, the middle and long distance events, and in race-walking events [5]. Hollings \& Hume (2011) found that $32 \%$ of the New Zealanders and $22 \%$ of the Australian WA WJC finalists subsequently became either finalists or medalists at the Commonwealth Games. From a sample of 1552 Jamaican track and field athletes who were finalist at a junior level, the 19\% progress to senior level [6]. Furthermore, a small percentage ( $9 \%$ of men and $13 \%$ of women) of athletes retained a top 20 national ranking at senior level, after been ranked in the top 20 at youth level [7].

In addition, $20.4 \%$ from the WA World Junior Championship finalists in middle- and long-distance track events ( $N=368$ finalists from six WJC), were among the top 10 best times at the WA world ranking during the next couple of years after their participation in WJC [3]. In another study, researchers analyzed the subsequent adulthood performance of the male middle-distance finalist runners at WA WYC and WJC, from 1998 to $2012(n=240)$, and found that $50 \%$ of the finalists at WJC participated in a WC and/or Olympic Games in subsequent years. In detail, for the WYC, they found that only $25.9 \%$ of these finalist participated in a WC $(2.67 \%)$, Olympic Games $(7.14 \%)$ or both $(15.17 \%)$ [8]. A similar study showed that the $88 \%$ from the 266 finalists at the 1999 WA WYC, made the world top 100 , but only $21 \%$ participated at the WA WC and/or Olympic Games between 2000 and 2004 , and the $9.39 \%$ of the athletes reached the top 10 [1]. A more recent study, concluded that only $17 \%$ of the male athletes and $21 \%$ of the female athletes ranked in the top 50 in U18, become top 50 ranked as senior athletes, in sprinting events [9]. Moreover, after analyzing 130 finalists at latest stages of junior competitions [4]. In general, is seems not possible to predict which athletes will become successful at senior events $[4,9]$, but some factors that may influence the pathway to success might be: later specialization involvement in other sports during adolescence and strong social support [10].
Previous studies have analyzed the athletes' subsequent rate of success as senior athletes. However, these analyses focus only on male athletes [8], specific events [3], specific countries [6,11], or transition to other events such as Olympic Games [4]. Therefore, the purpose of the present study was to determine the percentage of success of male and female finalist at WA World Youth Championship (WYC) (from 1999 to 2009) who also became finalists in a subsequent senior WA World Championship (WC), considering all events.

\section{Methodology}

\subsection{Participants}

The participants of this study were all the athletes who were finalists (ranked from first place to eight place) in 1999, 2001, 2003, 2005, 2007, and 2009 WA World U18 Championships -WYC-. A total of 1759 finalists from all events from the six championships were analyzed.

\subsection{Procedures}

This research is a cohort descriptive retrospective study. The first step was to code the athletes of the first 8 finalists (places 1 to 8 ), the final position, and the event's name for all events in the 1999, 2001, 2003, 2005, 2007, and 2009 WA WYC. Information was obtained from the data available in the WA 's web site (www.iaaf.org). Data was coded in an Excel worksheet designed for this research. The study was not submitted to an Institution Research Board (IRB) since all analyses were performed on publicly available information from WA's web site.

The second step was to search if the athlete previously coded was a finalist (ranked in the first eight places) in 2001, 2003, 2005, 2007, 2009, or 2011 World Championships.

The third step was to summarize the coded information into tables, to analyze the percentage of athletes who became finalists in the World Youth Championships, which later were also finalists in the World Championships (percentage of success). Figure 1 shows an example of how the information was obtained.

For the events which were different among WYC and senior WC, we searched for a similar event. For example, for the finalists in the $2000 \mathrm{~m}$ steeplechase in the WYC, we searched for the finalists in the $3000 \mathrm{~m}$ steeplechase in the World Championship. 


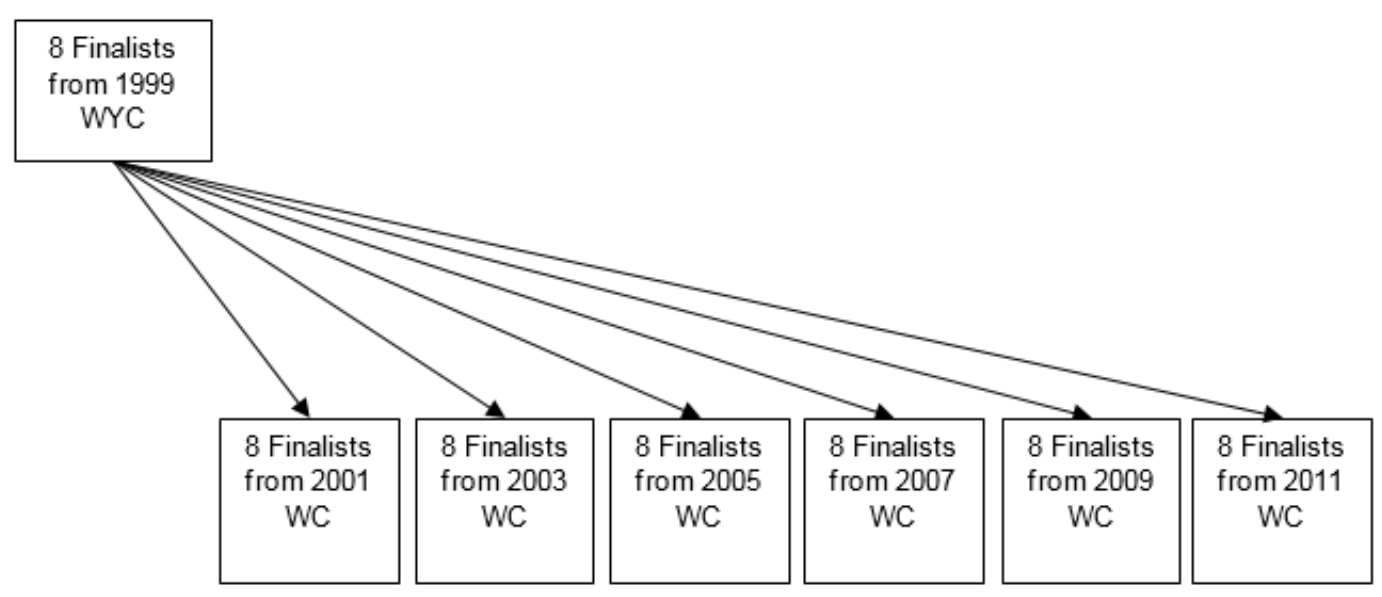

Figure 1. Flow diagram that shows the procedures of the data collection.

\subsection{Data Analysis}

Descriptive statistics as the percentage of success, tables, and graphics were used. Percentage of success was analyzed for all events together, field events, track events, and all events individually. Analyses were conducted with Excel Microsoft ${ }^{\circledR}$ software 2016.

\section{Results and Discussion}

For all the events, from 1759 finalists in the WYC in $1999,2001,2003,2005,2007$, or 2009 , only 83 , representing $4.72 \%$ were also finalists (first eight places) in a World Championship in 2001, 2003, 2005, 2007,2009 , or 2011. From those 83 athletes, 45 were men and 38 were women (see Figure 2). Hence, there is a $95.28 \%$ of failure, interpreted as not being able to achieve sport performance to be between the first 8 athletes in a Senior World Championship, after being between the first 8 athletes in a WYC.

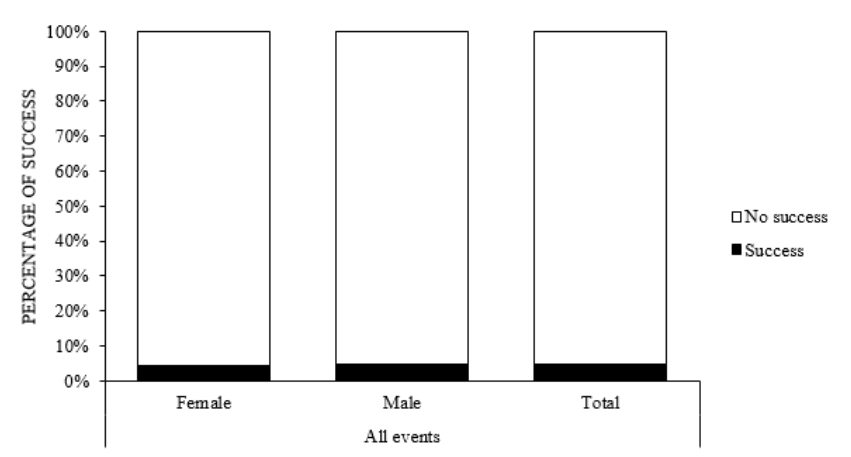

Figure 2. Percentage of success (and no success) for all finalists in World Youth Championship, who also became a finalist in a World Championship, for all the events by sex.
For the track events, we found a total success of $4.89 \%$; in males we found a rate of $3.39 \%$, in females the rate was $5.99 \%$. For a detailed analysis of each track event, see Table 1. For the field events, the success rate was $4.95 \%$, in males we found a rate of $3.39 \%$, in females the rate was $5.99 \%$. For a detailed analysis of each field event, see Table 2. The percentage of success by discipline is shown in Table 3. Results indicated that, for all the events, a small percentage of youth finalists in a WYC, became finalist at the World Championship. When analyzed by discipline, we found that the percentage of success is higher in the race-walking events and in the longdistance events, but still, it is less than $12 \%$.

Table 1. Percentage of success in track events for all finalists and by sex

\begin{tabular}{llll}
\hline \multirow{2}{*}{ Event } & \multicolumn{2}{l}{ Finalists } & \\
\cline { 2 - 4 } & Female & Males & Total \\
\hline $100 \mathrm{~m}$ & 8.70 & 6.25 & 7.45 \\
$200 \mathrm{~m}$ & 4.26 & 8.51 & 6.38 \\
$400 \mathrm{~m}$ & 4.17 & 4.26 & 4.21 \\
$800 \mathrm{~m}$ & 0.00 & 2.08 & 1.05 \\
$1500 \mathrm{~m}$ & 0.00 & 0.00 & 0.00 \\
$3000 \mathrm{~m}$ & 6.25 & 16.67 & 11.46 \\
$2000 \mathrm{~m}$ & 0.00 & 2.08 & 1.56 \\
steeplechase & & & \\
$100 \mathrm{~m}-110 \mathrm{~m}$ & 4.26 & 8.33 & 6.32 \\
hurdles & & & \\
$400 \mathrm{~m}$ hurdles & 2.08 & 2.13 & 2.11 \\
Race Walking & 2.08 & 12.50 & 7.29 \\
\hline
\end{tabular}


Table 2. Percentage of success in field events for all finalists and by sex

\begin{tabular}{llll}
\hline \multirow{2}{*}{ Event } & \multicolumn{2}{l}{ Finalists } & \\
\cline { 2 - 4 } & Female & Male & Total \\
\hline Discus Throw & 4.17 & 2.13 & 3.16 \\
Hammer & 10.42 & 2.08 & 6.25 \\
Throw & & & \\
Shot Put & 4.17 & 2.08 & 3.13 \\
Javelin Throw & 4.17 & 6.25 & 5.21 \\
High Jump & 6.25 & 6.25 & 6.25 \\
Long Jump & 6.25 & 2.08 & 4.17 \\
Pole Vault & 8.33 & 2.08 & 5.21 \\
Triple Jump & 4.17 & 8.33 & 6.25 \\
Combined & 0.00 & 0.00 & 0.00 \\
Events & & & \\
\hline
\end{tabular}

Table 3. Percentage of success in each discipline for all finalists and by sex

\begin{tabular}{llll}
\hline \multirow{2}{*}{ Discipline } & \multicolumn{2}{l}{ Finalists } & \\
\cline { 2 - 4 } & Female & Male & Total \\
\hline Sprints & 5.67 & 6.29 & 6.01 \\
$\begin{array}{l}\text { Middle-distance } \\
\text { running }\end{array}$ & 0.00 & 1.04 & 0.52 \\
$\begin{array}{l}\text { Long-distance } \\
\text { running }\end{array}$ & 6.25 & 16.67 & 11.46 \\
Hurdles & 2.70 & 4.20 & 3.54 \\
Jumps & 6.25 & 4.69 & 5.47 \\
Throws & 5.73 & 3.13 & 4.44 \\
Race Walking & 2.08 & 12.50 & 7.29 \\
Combined Events & 0.00 & 0.00 & 0.00 \\
\hline
\end{tabular}

The purpose of the present study was to examine the percentage of success of all WA World Youth Championship (WYC) finalists who also became finalists in a subsequent senior World Championship (WC). We found that only 83 athletes from 1759 succeeded, that is only $4.72 \%$ of the finalists in a WYC (from 1999 to 2009) were also finalists in a subsequent World Championship (from 2001 to 2011).
Our results are supported by previous studies, which also found a low rate of success when analyzing the success of the young and junior athletes in subsequent-adulthood performance $[1-3,5,7,8,11]$. This results are consistent at all events, for male and female $[2,5,8]$.

Expertise in sports is the result of the interaction of a variety of factors, which include biological, psychological, and sociological constraints, but also these factors may lead to athlete dropout [2]. Therefore, possible explanations for the small percentage of success achieved in a senior category after being a finalist in a younger category may be injuries, biological maturation, overtraining, and/or early specialization.

Early specialization is the result of focusing on the practice, training, and participation in a single sport in early childhood $[12,13]$. Evidence showed that early specialization (i.e. large amount of sport-specific practice) might result in negative consequences, including a lower performance as adults or a shorter athletic career $[12,14]$. In addition, some potential risks of early specialization are burnout and injuries [13], which may also lead to a non-successful subsequent-adulthood performance. Therefore, a possible explanation is that to be a finalist in a WYC, athletes had to achieve a maximum performance at a younger age given by an early specialization; which may lead to a shorter athletic career or lower adulthood performance, having as a consequence not being a finalist in a WC. This possibility is supported by one of the key factors needed to succeed stated by Huxley et al. (2017), which is later specialization [10].

Overtraining is a condition that can be defined as the imbalance of training and recovery; and is observed as chronic fatigue accompanied by physical (i.e. decline in physical performance) and psychological symptoms (i.e. loss of appetite, depression) $[15,16]$. It is important not to confuse overtraining with overuse injuries [15]. Parental pressure to compete and succeed, academic pressure, competitive level, training load, and gender are different factors that may contribute to overtraining $[17,18]$. However, recent research showed that training load is not a significant predictor of overtraining [19]. Evidence has shown an incidence from $20 \%$ to $30 \%$ in overtraining in young athletes, with a higher occurrence in individual sports athletes [18]. In addition, 29\% of English athletes reported having been nonfunctional, overreaching, or overtraining [19]. The time to prepare from WYC to WJC, and then to a WC suggests at least four years of 
training, which means a lot of stressful situations and training that may induce overtraining.

Evidence indicated that few young athletes have injuries due to training [20]. However, in a systematic review, the incidence of lower extremity injuries was reported to range between $19.4 \%$ and $79.3 \%$ in athletes, with knee injuries in male runners being the most prevalent for higher weekly training distances [21]. In addition, the highest incidence of injuries in jumpers is the patellar tendinitis, which is more common in men than in women [22,23]. Another injury reported by long-distance runners is the iliotibial band friction syndrome [22]. Overtraining and the presence of an injury may also lead to burnout; which may also lead to dropout $[13,17]$.

Biological maturation may be an advantage for some athletes, although some authors consider this is less likely [8]. Biological maturation or development rate of each system depends on genetics, therefore it is different for everyone [24,25]. In general, most athletes may reach their peak of maturation of most important systems at 16 years of age, at an age when they will be competing in WYC. However, not everyone reaches his/her peak-performance at the same age, it is possible to have late maturation, and therefore those athletes may reach their peak at 17,18 , or even 19 years old. Hence, if athletes reach their peak at 16 or 17 they will have an advantage in a WYC compared to athletes that may not reach their peak at that age. Nevertheless, this will not be an advantage when they compete at the WC. For example, in the 1999 WYC, athlete $A$ with 16 years of age may have reached peakmaturity, but athlete $B$ also with 16 years of age may not. In this WYC athlete A was a finalist due to the advantage from the systems' maturation, and athlete $B$ was not a finalist. Few years later in the WC, both athletes, now older, have reached peak maturity, now athlete $B$ was finalist and athlete $A$ (which now has no advantage) was not a finalist,

The low rate of success from WA WYC to WC was surprising and unexpected. Nonetheless, these results should prompt for reflection; especially if the reasons are injuries, overtraining or early specialization. We believe that success in a WC is the goal of every athlete and coach, and these results suggest that success in a WYC is not the right path for it. Hence, which may be the correct path? Are coaches and leaders taking the correct decisions for the athletes? Is the best decision to cancel the WYC from the International Calendar? Future research should focus on analyzing the possible causes to better understand these results.

This study based its results on the population data of all the female and male finalists from all the events at the WA WYC, from 1999 until 2009, who became finalist in subsequent WA WC. Which is a strength, considering most studies analyzed only female (5) or male (8) samples, or specific events $[2,8]$. Nonetheless, a limitation of this study is that the last WA WC analyzed was the 2011 WC, leaving out the possibility of 2009 WYC finalist to achieve success at subsequent WC (p.e. 2013, 2015 WA WC).

\section{Conclusion}

In general, the World Youth Championship finalists had a low percentage of success $(4.72 \%)$ of becoming a finalist in the senior World Championship. In track events, for male athletes, the higher percentage of success found was for $3000 \mathrm{~m}(16.67 \%)$, while for female athletes was the $100 \mathrm{~m}(8.70 \%)$. In field events, for male the higher percentage of success found for triple jump (8.33\%), for female was hammer throw $(10.42 \%)$. However, most of the finalists in a World Youth Championship will not be World Championship finalists. The results of the present study suggest that after being a World Youth Championship finalist it is more likely to fail in a World Championship than to succeed. Therefore, early sport success is a dead end.

\section{References}

[1] M. Grund, W. Ritzdorf, From talent to elite athlete: A study of the performance development of the finalists at the 1999 IAAF World Youth Athletics Championships, New Studies in Athletics, 21 (2006) 43-55.

[2] G. Boccia, P. Moise, A. Franceschi, F. Trova, D. Panero, A. La Torre, A. Rainoldi, F. Schena, M. Cardinale, Career Performance Trajectories in Track and Field Jumping Events from Youth to Senior Success: The Importance of Learning and Development, Plos One, 12 (2017) 1-15. [DOI]

[3] F. Pizzuto, M. Bonato, G. Vernillo, A. La Torre, M.F. Piacentini, Are the World Junior Championship Finalists for Middle- and LongDistance Events Currently Competing at International Level?, International journal of 
sports physiology and performance, 12 (2017) 316-321. [DOI]

[4] J.L. Foss, J.A. Sinex, R.F. Chapman, Career Performance Progressions of Junior and Senior Elite Track and Field Athletes, Journal of Science in Sport and Exercise, 1 (2019) 168175. [DOI]

[5] N. Brito, A. Fonseca, R. Rolim, Os melhores atletas nos escalões de formação serão igualmente os melhores atletas no escalão sénior? Análise centrada nos rankings femininos das diferentes disciplinas do Atletismo ao longo das últimas duas décadas em Portugal, Revista Portuguesa de Ciências do Desporto, 4 (2004) 17-28.

[6] E. Campbell, R. Irving, M. Poudevigne, L. Dilworth, S. McFarlane, O. Ismail, Janel Bailey, Contextual factors and sporting success: The relationship between birth date and place of early development on the progression of Jamaican track and field athletes from junior to senior level, Plos One, 14 (2019) e0227144. [DOI] | [PubMed]

[7] P.E. Kearney, P.R. Hayes, Excelling at youth level in competitive track and field athletics is not a prerequisite for later success, Journal of sports sciences, 36 (2018) 2502-2509. [DOI]

[8] K. Bálint, G. Zsolt, B. Otto, (2015) Study of the youth and junior world championships finalist adult performance depending on the places, Educatio Artis Gymnasticae.

[9] G. Boccia, M. Cardinale, P.R. Brustio, WorldClass Sprinters' Careers: Early Success Does Not Guarantee Success at Adult Age, International Journal of Sports Physiology and Performance, 16 (2020) 367-74.

[10] D.J. Huxley, D. O'Connor, P. Larkin, The pathway to the top: Key factors and influences in the development of Australian Olympic and World Championship Track and Field athletes, International Journal of Sports Science \& Coaching, 12 (2017) 264-275. [DOI]

[11] S. Hollings, P. Hume, Progression of elite New Zealand and Australian junior athletes to senior representation, New Studies in Athletics, 26 (2011) 127-135.

[12] J. Baker, S. Cobley, J. Fraser-Thomas, what do we know about early sport specialization? Not much!, High Ability Studies, 20 (2009) 77-89. [DOI]

[13] R.M. Malina, Early Sport Specialization: Roots, Effectiveness, Risks, Current sports medicine reports, 9 (2010) 364-371. [DOI] I [PubMed]

[14] M. Wall, J. Côté, Developmental activities that lead to dropout and investment in sport, Physical Education and Sport Pedagogy, 12 (2007) 77-87. [DOI]

[15] A. Griffin, V. Unnithan, Overtraining in child athletes, Journal of Bodywork and Movement Therapies, 3 (1999) 92-96. [DOI]

[16] H. Kuipers, H.A. Keizer, Overtraining in Elite Athletes, Sports Medicine, 6 (1988) 79-92. [DOI]

[17] J.S. Brenner, Overuse injuries, overtraining, and burnout in child and adolescent athletes, Pediatrics, 119 (2007) 1242-1245. [DOI]

[18] R. Winsley, N. Matos, Overtraining and Elite Young Athletes, The elite young athlete, 56 (2011) 97-105. [DOI]

[19] N.F. Matos, R.J. Winsley, C.A. Williams, Prevalence of nonfunctional overreaching/overtraining in young English athletes, Medicine \& Science in Sports \& Exercise, 43 1(2011) 287-294. [DOI] । [PubMed]

[20] D.J. Hunter, F. Eckstein, Exercise and osteoarthritis, Journal of anatomy, 214 (2009) 197-207. [DOI] | [PubMed]

[21] R.N. Van Gent, D. Siem, M. van Middelkoop, A.G. Van Os, S.M.A. Bierma-Zeinstra, B.W. Koes, Incidence and determinants of lower extremity running injuries in long distance runners: a systematic review, British journal of sports medicine, 41(2007) 469-480. [DOI] । [PubMed]

[22] A. Ivković, M. Franić, I. Bojanić, M. Pećina, Overuse Injuries in Female Athletes, Croatian medical journal, 48 (2007) 767-778. [DOI] । [PubMed]

[23] C.P. Gabbard, (2011) Lifelong Motor Development, Benjamin Cummings, USA.

[24] A. Viru, J. Loko, M. Harro, A. Volver, L. Laaneots, M. Viru, Critical Periods in the Development of Performance Capacity During 
Childhood and Adolescence, European Journal of Physical Education, 4 (1999) 75-119. [DOI]

\section{Acknowledgement}

The authors will like to thank Luis Fernando AragónVargas, PhD/FACSM; for his assistance to improve the writing of the paper.

\section{Funding}

No funding was received for conducting this study.

\section{Authors Contribution}

María Moreno - Study design, methods, data collection and performed the analysis; Judith Jiménez-Díaz - Contribute to study design and wrote the paper; Walter Salazar - Study design, methods, data collection and performed the analysis. All the authors read and approved the final version of the manuscript.

\section{Ethics Approval}

This study was approved by Institutional Ethics Committee

\section{Informed Consent}

Written informed consent was obtained from the participants

\section{Conflict of interest}

The Authors have no conflicts of interest to declare that they are relevant to the content of this article.

\section{Does this article screened for similarity?}

Yes

\section{About The License}

(C) The Author(s) 2021. The text of this article is open access and licensed under a Creative Commons Attribution 4.0 International License 